\title{
Dietary fat and breast cancer in Saudi Arabia: a case-control study
}

A. Alothaimeen, ${ }^{1}$ A. Ezzat, ${ }^{2}$ G. Mohamed, ${ }^{1}$ T. Muammar ${ }^{3}$ and A. Al-Madouj

$$
\begin{aligned}
& \text { الدهن الغذائي وسرطان الثدي في المملكة العربية السعودية: دراسة للحالات والشوراهد }
\end{aligned}
$$

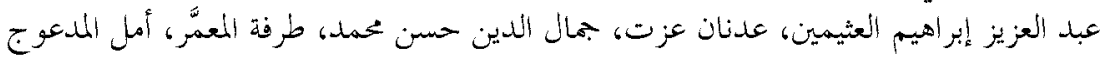

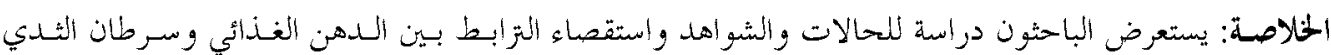

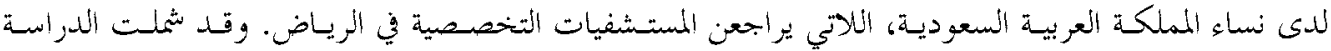

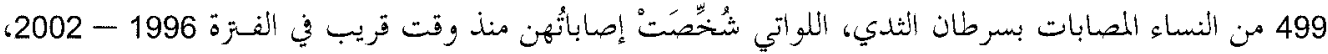

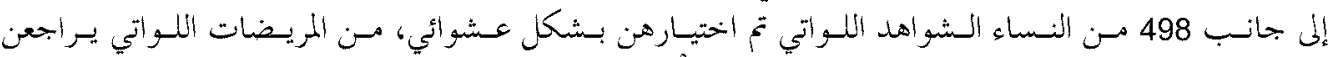

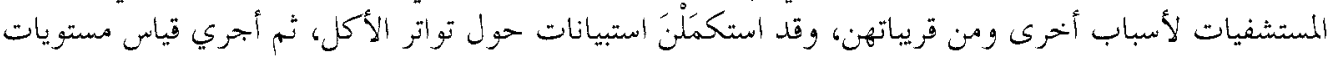

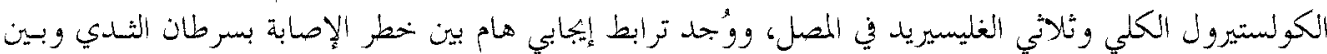

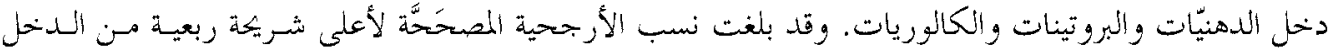

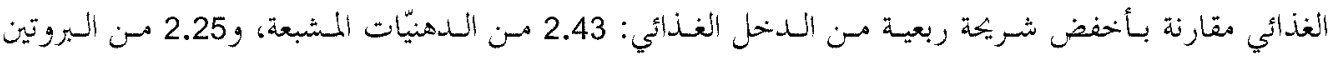

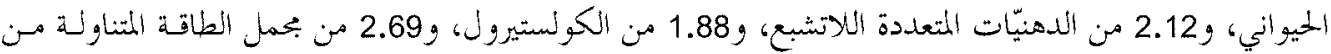

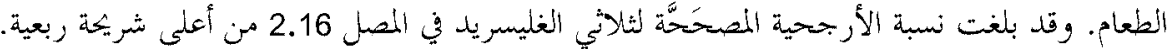

ABSTRACT A case-control study investigated the association between dietary fat and breast cancer in Saudi Arabian women attending a specialist hospital in Riyadh. Women with breast carcinoma $(n=499)$ newly diagnosed between 1996-2002, and control women $(n=498)$ randomly selected from patients' attendants and relatives, completed a food frequency questionnaire. Serum levels of triglycerides and total cholesterol were measured. A significant positive association was found between risk of breast cancer and intake of fats, protein and calories. Adjusted odds ratios for the highest quartile of intake versus the lowest were 2.43 for saturated fat, 2.25 for animal protein, 2.12 for polyunsaturated fat, 1.88 for cholesterol and 2.69 for total energy from dietary intake. For serum triglycerides the adjusted odds ratio was 2.16 for the highest quartile.

\section{Les graisses alimentaires et le cancer du sein en Arabie saoudite : étude cas-témoins}

RÉSUMÉ Une étude cas-témoins a été réalisée pour examiner l'association entre les graisses alimentaires et le cancer du sein chez des femmes saoudiennes consultant dans un hôpital spécialisé à Riyad. Des femmes ayant un cancer du sein $(n=499)$ nouvellement diagnostiqué entre 1996 et 2002, et des femmes témoins $(n=498)$ choisies de manière aléatoire parmi les aidants et les parents des patientes ont rempli un questionnaire sur la fréquence de consommation alimentaire. Les taux sériques de triglycérides et de cholestérol total ont été mesurés. Une association positive significative a été observée entre le risque de cancer du sein et l'apport de graisses, de protéines et de calories. Le risque relatif ajusté pour le quartile de l'apport le plus élevé par rapport au quartile le plus bas était de 2,43 pour les graisses saturées, de 2,25 pour les protéines animales, de 2,12 pour les graisses polyinsaturées, de 1,88 pour le cholestérol et de 2,69 pour l'énergie totale provenant de l'apport alimentaire. Pour les triglycérides sériques, le risque relatif ajusté était de 2,16 pour le quartile le plus élevé.

${ }^{1}$ Department of Biostatistics, Epidemiology and Scientific Computing, Nutrition Research; ${ }^{2}$ Department of Oncology, ${ }^{3}$ Department of Family Medicine and Polyclinics, King Faisal Specialist Hospital and Research Centre, Riyadh, Saudi Arabia.

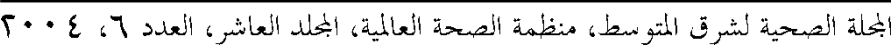




\section{Introduction}

A large body of evidence has accumulated concerning the association between diet and breast cancer. Much of this has focused on the possible causative role of dietary fat. These studies have provided somewhat inconsistent support for an association between fat intake and breast cancer [1]. Conclusions from some casecontrol studies have suggested a positive association between breast cancer and saturated fat intake [2], whereas others demonstrated a reduced risk due to total and polyunsaturated fat intake [3]. A prominent Harvard cohort study of nearly 90000 American nurses compared nurses who ate low-fat diets with nurses who consumed higher fat diets and concluded that no relationship existed between the risk of breast cancer and the amount of fat consumed [4]. Willett's review of epidemiological studies of the relationship between diet and breast and colon cancers suggested there was a null or weak association between dietary fat and breast cancer [5].

In Saudi Arabia, breast cancer is becoming a major health risk and is the most common female malignancy in the country [6-8]. Several studies have shown an upward trend in the incidence of breast cancer in Saudi Arabia [9-13]. Breast malignancy had the highest relative frequency in the eastern region of Saudi Arabia during 1981-83 in relation to previous studies [9]. This shows an upward trend in that region as it rose from the third most common cancer during 1952-60 to the second most common in 1962-73 [10]. However, it is the sixth most common malignancy in the southern region [11], and for females it is the most common cancer [12]. The number of breast cancer cases registered at King Khalid University Hospi- tal, Riyadh were 47, 48 and 107 during the periods $1985-87,1988-90$ and 1990-93 respectively and breast cancer was the second most common malignancy among females in that hospital [13]. Data suggests that breast cancer in Saudi Arabia occurs in a relatively younger age group compared with industrialized countries. The mean age of Saudi women with breast cancer is 47 years as compared with 54 years in Western Europe and America [9].

With increasing prosperity and commercial exposure of the population of Saudi Arabia, there has been an influx of western affluence foods over the last 3 decades. The increased consumption of new types of food, which are rich in fat, meat and refined carbohydrates, may be a contributory factor for the increase in breast cancer incidence in Saudi Arabia. The national nutrition survey of the population of Saudi Arabia showed that per capita energy intake in Saudi Arabia rose from $1801 \mathrm{kcal}$ in 1971 to $3082 \mathrm{kcal}$ in 1992 [14,15]. Percent of energy from carbohydrates decreased from $75 \%$ to $43 \%$ and from fat increased from $10 \%$ to $42 \%$ during the same period. Protein intake increased from $49 \mathrm{~g} /$ day in 1971 to $114 \mathrm{~g} /$ day in 1992 , with $60 \%$ of protein intake from animal sources, while fat intake increased from $34 \mathrm{~g}$ to $144 \mathrm{~g}$ during the same period.

Despite concerns about changing dietary habits and the incidence of breast cancer in Saudi Arabia, no study has investigated the association between diet and breast cancer among Saudi females. Therefore, this case-control study at a specialist hospital in Riyadh was conducted to investigate if there is an association between breast cancer and dietary risk factors, including high protein, fat and calorie intake, high body mass index (BMI) and raised serum cholesterol and trigycerides levels. 


\section{Methods}

\section{Sample}

This was a case-control study of women attending the breast cancer clinic at King Faisal Specialist Hospital and Research Centre in Riyadh. Patients attending the hospital are referred from all areas of the country.

The sample size was estimated by assuming the proportion with high fat intake among controls is 9\% and among cases $15 \%$ to give an odds ratio of 1.78 as an indication of a significant association between fat intake and breast cancer $(\alpha=$ $0.05,1-\beta=0.80)$. Using Epi-Info, version 6 , the number of cases required was 500 and controls 500 .

The cases were recruited prospectively in the order in which they came to the clinic and were women with newly diagnosed, histopathologically confirmed breast cancer. Control women were selected from the patients' attendants and relatives, frequency matched for age, parity, breastfeeding practice and age at marriage. Data collection took place from September 1996 to April 2002.

The women were enrolled after giving informed consent. Approval for the study was obtained from the Ethics Committee of the Research Centre of King Faisal Specialist Hospital.

\section{Dietary study}

An existing food frequency questionnaire, used in the National Nutrition Survey for Saudi Arabia [14], was modified to accommodate the food habits of Saudis. To help record the usual intake of food items accurately we used food models. The 40 food items listed in the questionnaire were: beef, lamb, poultry, fish, camel meat, goat meat, eggs, corn oil, olive oil, sunflower oil, gheel samnah, butter, shaham, ghusdah, tahinah, other fats and oils, salt, pepper, sauces, vegetables, fruits, cow's milk, laban milk, yoghurt, cheese, powdered milk, camel's milk, goat's milk, concentrated milk, sweetened condensed milk, milk with other flavours, tea with milk, coffee with milk, coffee without milk, bran flakes, corn, bread, rice, cakes, pie, pudding, ice cream, crème caramel. The food frequency questionnaire was administered by interview using well-trained nutritionists. Intake frequencies were expressed as number of times each item was consumed per week. The food frequency data were crosschecked with a 3-day food record.

A risk factors questionnaire collected demographic, anthropometric and reproductive information from cases and controls. It included questions on nationality, residence, age, age at menarche, menopausal status, breastfeeding, number of pregnancies, number of abortions, history of oral contraceptive use, family history of breast cancer, weight and height (for calculation of body mass index).

Serum levels of total cholesterol and triglycerides were obtained for patients and controls. For patients, the data was extracted from the laboratory records. For controls, a blood sample was taken and analysed at the hospital laboratory.

Diet analysis software (NSL Diet Analyzer and WinDiet version 5) and Saudi food tables [14] were used to indirectly calculate nutrients from reported intakes of individual foods. We calculated the daily intake of: total energy (kcal), total fat $(\mathrm{g})$, saturated fat $(\mathrm{g})$, polyunsaturated fat $(\mathrm{g})$, protein $(\mathrm{g})$ and cholesterol $(\mathrm{mg})$ from the self-reported food consumption and validated against the 3-day food record. One case and 2 controls were excluded from the analysis because of unacceptably low or high nutrient values. Thus data from 499 cases and 498 controls were analysed.

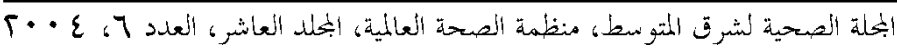




\section{Statistical analysis}

Means and standard deviations (SD) were compared using the $t$-test and frequencies using the chi-squared test. Odds ratios were estimated and 95\% confidence intervals (CI) from multiple logistic regression, adjusting for the following potential confounding factors: age, nationality, province and menopausal status. We modelled nutrients across quartiles using the first quartile as the reference group. A $P$-value less than 0.05 was considered significant.

\section{Results}

Table 1 shows the demographic and reproductive characteristics of the study sample. Breast cancer cases relative to controls in this study group were older $(P<0.001)$, less heavy $(P<0.01)$ and shorter $(P<$
0.0001) with similar BMI, had more pregnancies $(P<0.0001)$, had a higher age at menarche $(P<0.05)$ and were less likely to have ever-used oral contraceptives $(P<$ $0.01)$.

Table 2 shows the relationship between breast cancer and serum triglycerides level, cholesterol level and BMI for the case and control samples analysed at the 25th, 50th and 75 th percentiles. Univariate analyses showed that cases and controls had no significant association between serum cholesterol level and BMI and breast cancer. However, the cases had significantly higher serum triglycerides levels than the control women. The multivariate odds ratio for raised trigycerides level, adjusted for age, nationality, province and menopause, was $2.16(95 \% \mathrm{CI}: 1.21-3.88)$ at the highest quartile $(P<0.05)$.

Table 1 Demographic and reproductive characteristics of breast cancer cases and control women

\begin{tabular}{lccc}
\hline Characteristics & \multicolumn{2}{c}{ Mean (SD) values } & Pases \\
& $(\boldsymbol{n}=\mathbf{4 9 9 )}$ & $\begin{array}{c}\text { Controls } \\
(\boldsymbol{n}=\mathbf{4 9 8})\end{array}$ & \\
\hline Age (years) & $44.8(11.5)$ & $36.8(12.8)$ & 0.0001 \\
Age at menarche (years) & $13.2(1.5)$ & $13.0(1.6)$ & 0.037 \\
Age at menopause (years) & $48.2(7.6)$ & $47.9(8.1)$ & 0.759 \\
Age at first delivery (years) & $20.6(4.9)$ & $20.7(4.5)$ & 0.759 \\
Age at marriage (years) & $20.6(4.8)$ & $20.7(12.1)$ & 0.174 \\
Number of pregnancies & $6.6(3.8)$ & $5.3(3.8)$ & 0.0001 \\
Number of abortions & $1.0(1.4)$ & $1.0(1.4)$ & 0.968 \\
Weight at diagnosis (kg) & $70.0(15.3)$ & $72.4(14.9)$ & 0.014 \\
Height at diagnosis (cm) & $154.1(6.7)$ & $157.1(6.5)$ & 0.0001 \\
Body mass index (kg/m $\left.{ }^{2}\right)$ & $29.5(6.2)$ & $29.4(6.2)$ & 0.818 \\
\% ever-used oral contraceptives & 54.1 & 62.5 & 0.013 \\
\% breastfeeding & 89.7 & 85.9 & 0.094 \\
\% family history of breast cancer & 15.0 & 12.1 & 0.174 \\
\hline
\end{tabular}

$\mathrm{n}=$ number of women.

$\mathrm{SD}=$ standard deviation . 


\begin{tabular}{|c|c|c|c|c|}
\hline \multicolumn{5}{|c|}{ Eastern Mediterranean Health Journal, Vol. 10, No. 6, 2004} \\
\hline \multicolumn{5}{|c|}{$\begin{array}{l}\text { Table } 2 \text { Relation between breast cancer and serum lipid levels and body mass index for case } \\
\text { and control women analysed by quartiles }\end{array}$} \\
\hline Variables (quartiles) & $\begin{array}{c}\text { No. of } \\
\text { cases/ } \\
\text { controls }\end{array}$ & $\begin{array}{l}\text { Crude odds ratio } \\
(95 \% \mathrm{Cl})\end{array}$ & $\begin{array}{c}\text { Age/province } \\
\text { adjusted odds } \\
\text { ratio }(95 \% \mathrm{Cl})\end{array}$ & $\begin{array}{c}\text { Multivariate } \\
\text { adjusted odds } \\
\text { ratio }(95 \% \mathrm{Cl})\end{array}$ \\
\hline \multicolumn{5}{|l|}{ Triglycerides (mM/L) } \\
\hline$<0.9$ & $47 / 95$ & 1 (reference) & 1 (reference) & 1 (reference) \\
\hline $0.9-1.3$ & $54 / 80$ & $1.36(0.84-2.23)$ & $1.03(0.60-1.74)$ & $0.73(0.40-1.32)$ \\
\hline$>1.3-2.0$ & $75 / 68$ & $2.23(1.38-3.60)^{\star *}$ & $1.75(1.04-2.94)^{*}$ & $1.67(0.96-2.93)$ \\
\hline$>2.0$ & $77 / 53$ & $2.90(1.79-4.81)^{\star * *}$ & $2.21(1.29-3.79)^{\star *}$ & $2.16(1.21-3.88)^{*}$ \\
\hline \multicolumn{5}{|l|}{ Cholesterol (mM/L) } \\
\hline$<4.3$ & $122 / 140$ & 1 (reference) & 1 (reference) & 1 (reference) \\
\hline $4.3-5.0$ & $117 / 115$ & $1.67(0.82-1.67)$ & $0.95(0.64-1.41)$ & $0.80(0.51-1.25)$ \\
\hline$>5.0-5.7$ & $140 / 131$ & $1.23(0.87-1.72)$ & $1.05(0.72-1.54)$ & $0.92(0.59-1.43)$ \\
\hline$>5.7$ & $120 / 112$ & $1.23(0.86-1.75)$ & $1.13(0.76-1.68)$ & $0.96(0.63-1.55)$ \\
\hline \multicolumn{5}{|l|}{ Body mass index $\left(\mathrm{kg} / \mathrm{m}^{2}\right)$} \\
\hline$<24.9$ & $113 / 135$ & 1 (reference) & 1 (reference) & 1 (reference) \\
\hline $24.9-28.9$ & $131 / 118$ & $1.33(0.93-1.89)$ & $0.91(0.61-1.36)$ & $0.80(0.51-1.25)$ \\
\hline$>28.9-33.5$ & $125 / 124$ & $1.20(0.85-1.71)$ & $0.69(0.46-1.03)$ & $0.92(0.59-1.43)$ \\
\hline$>33.5$ & $128 / 120$ & $1.27(0.89-1.81)$ & $0.66(0.44-0.99)$ & $0.99(0.63-1.55)$ \\
\hline
\end{tabular}

${ }^{a}$ Adjusted for age, nationality, province and menopause.

${ }^{*} \mathrm{P}<0.05 ;{ }^{* *} \mathrm{P}<0.01 ;{ }^{* *} \mathrm{P}<0.001$.

$\mathrm{Cl}=$ confidence interval.

Table 3 shows the association between breast cancer and daily intake of different nutrients for the cases and controls analysed at the 25th, 50th and 75th percentiles of the recommended daily allowance. Crude and adjusted odds ratios of these nutritional factors in relation to breast cancer are also given. Univariate analysis showed that cases and controls were similar in intake of total protein, but cases had significantly lower intake of energy and of all the components of fat (total fat, saturated and polysaturated fats) relative to controls $(P<$ $0.05)$. When adjusted for age and province, none of the nutrition variables showed an association with breast cancer.

Table 3 also presents the odds ratios for the intake of various nutrients to breast cancer after adjustment for age, nationality, province, menopause and triglycerides lev- els. This analysis showed that the intake of protein was significantly related to breast cancer risk after adjustment for other possible confounding factors. Multivariate adjustment reversed the associations noted earlier between breast cancer and the various dietary components. The adjusted odds ratios for the highest quartile of intake versus the lowest were 2.43 (95\% CI: $1.36-$ 4.34) for saturated fat, $2.25(95 \% \mathrm{CI}$ : 1.27-3.99) for animal protein, $2.12(95 \%$ CI: 1.17-3.83) for polyunsaturated fat, 1.88 (95\% CI: 1.03-3.44) for cholesterol, 2.69 (95\% CI: $1.51-4.81)$ for total energy obtained from fat, and 2.16 (95\% CI: $1.21-$ 3.88) for triglycerides. It is worth noting that the association between triglycerides and the risk of breast cancer remained significantly positive irrespective of all other variables investigated (Table 2).

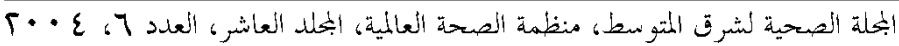


Table 3 Relationship between breast cancer and self-reported daily intake of dietary nutrients for case and control women analysed by quartiles

\begin{tabular}{|c|c|c|c|c|}
\hline $\begin{array}{l}\text { Daily intake of } \\
\text { nutrient (quartiles) }\end{array}$ & $\begin{array}{c}\text { No. of } \\
\text { cases/ } \\
\text { controls }\end{array}$ & $\begin{array}{l}\text { Crude odds } \\
\text { ratio }(95 \% \text { Cl) }\end{array}$ & $\begin{array}{l}\text { Age/province } \\
\text { adjusted odds } \\
\text { ratio }(95 \% \mathrm{Cl})\end{array}$ & 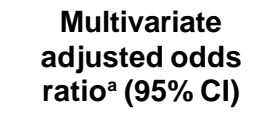 \\
\hline \multicolumn{5}{|c|}{ Total energy from fat (kcal) } \\
\hline$<1084.1$ & $131 / 118$ & 1 (reference) & 1 (reference) & 1 (reference) \\
\hline $1084.1<1426.2$ & $130 / 119$ & $0.98(0.69-1.40)$ & $1.24(0.84-1.83)$ & $2.65(1.44-4.86)^{* *}$ \\
\hline $1426.2<1872.9$ & $132 / 118$ & $1.00(0.71-1.43)$ & $1.27(0.85-1.88)$ & $3.19(1.74-5.83)^{\star \star \star}$ \\
\hline$>1872.9$ & $106 / 143$ & $0.67(0.47-0.95)^{*}$ & $0.84(0.56-1.24)$ & $2.69(1.51-4.81)^{\star *}$ \\
\hline \multicolumn{5}{|l|}{ Total protein $(g)$} \\
\hline$<52.2$ & $127 / 122$ & 1 (reference) & 1 (reference) & 1 (reference) \\
\hline $52.2<68.9$ & $130 / 119$ & $1.05(0.74-1.49)$ & $1.14(0.77-1.68)$ & $2.65(1.41-4.98)^{\star *}$ \\
\hline $68.9<88.1$ & $135 / 115$ & $1.13(0.79-1.60)$ & $1.16(0.78-1.72)$ & $3.12(1.71-5.70)^{* * *}$ \\
\hline$>88.1$ & $107 / 142$ & $0.72(0.51-1.03)$ & $0.74(0.50-1.09)$ & $2.25(1.27-3.99)^{\star *}$ \\
\hline \multicolumn{5}{|l|}{ Total fat $(g)$} \\
\hline$<35.4$ & $134 / 115$ & 1 (reference) & 1 (reference) & 1 (reference) \\
\hline $35.4<51.1$ & $128 / 121$ & $0.91(0.64-1.29)$ & $1.08(0.73-1.60)$ & $1.65(0.90-3.02)$ \\
\hline $51.1<70.9$ & $138 / 112$ & $1.06(0.74-1.50)$ & $1.34(0.91-1.99)$ & $2.67(1.47-4.83)^{\star *}$ \\
\hline$>70.9$ & $99 / 150$ & $0.57(0.40-0.81)^{\star *}$ & $0.73(0.49-1.09)$ & $1.64(0.92-2.95)$ \\
\hline \multicolumn{5}{|l|}{ Polyunsaturated fat $(g)$} \\
\hline$<19.9$ & $138 / 111$ & 1 (reference) & 1 (reference) & 1 (reference) \\
\hline $19.9<30.4$ & $127 / 122$ & $0.84(0.59-1.19)$ & $0.96(0.65-1.41)$ & $2.15(1.17-3.92)^{*}$ \\
\hline $30.4<41.3$ & $126 / 124$ & $0.82(0.58-1.16)$ & $1.12(0.76-1.67)$ & $2.43(1.30-4.53)^{\star *}$ \\
\hline$>41.3$ & $108 / 141$ & $0.62(0.43-0.88)^{\star *}$ & $0.78(0.53-1.16)$ & $2.43(1.36-4.34)^{\star *}$ \\
\hline \multicolumn{5}{|l|}{ Polyunsaturated fat (g) } \\
\hline$<15.6$ & $131 / 118$ & 1 (reference) & 1 (reference) & 1 (reference) \\
\hline $15.6<21.3$ & $144 / 105$ & $1.23(0.87-1.76)$ & $1.56(1.05-2.31)$ & $2.19(1.18-4.07)^{*}$ \\
\hline $21.3<29.2$ & $124 / 126$ & $0.89(0.62-1.26)$ & $1.15(0.78-1.70)$ & $2.73(1.53-4.87)^{\star *}$ \\
\hline$>29.2$ & $100 / 149$ & $0.61(0.42-0.86)^{\star \star}$ & $0.78(0.52-1.15)$ & $2.12(1.17-3.83)^{*}$ \\
\hline \multicolumn{5}{|l|}{ Cholesterol (mg) } \\
\hline$<169.6$ & $135 / 114$ & 1 (reference) & 1 (reference) & 1 (reference) \\
\hline $169.6<266.4$ & $128 / 121$ & $0.89(0.63-1.27)$ & $1.00(0.68-1.48)$ & $1.64(0.90-2.98)$ \\
\hline $266.4<400.7$ & $125 / 125$ & $0.84(0.59-1.20)$ & $0.99(0.67-1.46)$ & $2.11(1.16-3.84)^{*}$ \\
\hline$>400.7$ & $111 / 138$ & $0.68(0.48-0.97)^{*}$ & $0.81(0.55-1.20)$ & $1.88(1.03-3.44)^{*}$ \\
\hline
\end{tabular}

${ }^{a}$ Adjusted for age, nationality, province, menopause and triglycerides.

${ }^{*} \mathrm{P}<0.05 ;{ }^{* *} \mathrm{P}<0.01 ;{ }^{* *} \mathrm{P}<0.001$.

$\mathrm{Cl}=$ confidence interval.

\section{Discussion}

Breast cancer is the most common cancer among women in Saudi Arabia. The number of reported cases of breast cancer in Saudi Arabia in 1999-2000 was 1157 (out of a female population of 7788754 ) [8]. There is no available data showing the number of deaths that can be attributed to breast cancer in Saudi Arabia. The descriptive epidemiology of breast cancer has 
demonstrated a rapid increase in the incidence rates in developing countries $[16,17]$. Identification of the contributing factors for the increasing rate would contribute substantially to our understanding of the epidemiology of breast cancer [16]. Environmental factors rather than genetic factors have been considered as the reason for variation in breast cancer rates among countries [17].

Socioeconomic development is normally associated with increasing wealth, changing lifestyle, disease pattern and increasing life expectancy. This association of changes, known as epidemiologic transition, is seen in many parts of the world and is very well demonstrated in Saudi Arabia, which has experienced rapid socioeconomic changes during the last 3 decades. As food habits mimic changes in lifestyle, there has been a dramatic shift from traditional foods which are based on whole wheat flour, milk and dates towards an affluent diet which is rich in total calories, meat, fat and refined carbohydrates. This change in dietary habit may be related to the increase in the number of breast cancer cases in Saudi Arabia [6-8].

Dietary fat has been proposed as one of the etiologic factors for breast cancer $[2,4,5]$. However, the relationship between fat intake and the risk of breast cancer has been examined in a number of case-control and cohort studies. The findings reported in the literature are not conclusive enough to establish a pattern for the real cause of the disease $[4,5]$.
Our data suggest that, among women living in Saudi Arabia, a diet that is high in fat predisposes to breast cancer development. In terms of nutrients, this high-risk dietary profile translates to a modest, positive association with total fat intake, saturated fat, and cholesterol. This is in contrast to an earlier study, which has cast doubt on a positive association between dietary fat and breast cancer [4]. However, our findings agree with those of Toniolo et al. [18] and Zaridze et al. [19] who showed a positive association between high dietary fat intake and breast cancer. Also high animal protein intake was significantly associated with breast cancer in our study, which supports the findings of De Stefeni et al. [20] and Levi et al. [21] who showed a positive relationship between high dietary meat consumption and breast cancer. Boyd et al. in their quantitative summary of all papers published up to July 2003 on dietary fat and the risk of breast cancer found intake of saturated fat and meat consumption is associated with an increased risk of breast cancer [22].

High consumption of sugar-rich foods, meat and other animal products rich in saturated fats has been recorded in Saudi Arabia [Khan MA, unpublished report, 1996]. Despite the inconclusive evidence about diet and disease, it is important to educate the population about the possibility of a link between dietary habits and cancer and to encourage them to adopt a diet that is low in calories, saturated fat and meat intake.

\section{References}

1. Hunter DJ, Willett WC. Diet, body size and breast cancer. Epidemiologic reviews, 1993, 15:110-32.

2. Howe GR et al. Dietary factors and risk of breast cancer: combined analysis of 12 case-control studies. Journal of the $\mathrm{Na}$ tional Cancer Institute, 1990, 82:561-9.

3. Vatten LJ, Solvoll K, Loken EB. Frequency of meat and fish intake and risk of breast cancer in a prospective study of

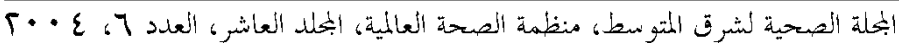


14,500 Norwegian women. International journal of cancer, 1990, 46:12-5.

4. Willett WC et al. Dietary fat and fiber in relation to risk of breast cancer. An 8year follow-up. Journal of the American Medical Association, 1992, 268:203744.

5. Willett WC. The search for the causes of breast and colon cancer. Nature, 1989, 338:389-94.

6. Annual report of the Tumor Registry. Riyadh, Saudi Arabia, King Faisal Specialist Hospital and Research Centre, 1996.

7. Ezzat A et al. An overview of breast cancer. Annals of Saudi medicine, 1997, 17(1):10-5.

8. National Cancer Registry. Cancer incidence report 1999-2000. Riyadh, Ministry of Health, 2000.

9. Amr SS et al. The spectrum of breast diseases in Saudi Arab females: a 26-year pathological survey at Dhahran health center. Annals of Saudi medicine, 1995, 15(2):125-32.

10. Rabadi SJ. Cancer at Dhahran health center, Saudi Arabia. Annals of Saudi medicine, 1987, (4):288-93.

11. Tandon P et al. Cancer in the Gizan Province of Saudi Arabia: an eleven year study. Annals of Saudi medicine, 1995, 15(1):14-20.

12. Koriech OM, Al-Kuhaymi R. Profile of cancer in Riyadh Armed Forces Hospital. Annals of Saudi medicine, 1994, 14(3):187-94.

13. Ajarim DD. Cancer at King Khalid University Hospital, Riyadh. Annals of Saudi medicine, 1992, 12:76-82.
14. Evaluation of the nutritional status of the people of Saudi Arabia. Riyadh, Saudi Arabia, King Abdulaziz City for Science and Technology, 1991.

15. Al Kanhal MA et al. A field study of the nutritional status of the people of Saudi Arabia (preliminary report). Second Symposium on Nutrition, College of Agriculture, King Saud University, 4-7 November 1994.

16. Kelsey JL, Horn-Ross PL. Breast cancer: magnitude of the problem and descriptive epidemiology. Epidemiologic reviews, 1993, 15(1):7-16.

17. Ziegler RG et al. Migration patterns and breast cancer risk in Asian-American women. Journal of the National Cancer Institute, 1993, 85:1819-27.

18. Toniolo $\mathrm{P}$ et al. Calorie providing nutrients and risk of breast cancer. Journal of the National Cancer Institute, 1989, 81: 278-86.

19. Zaridze D et al. Diet, alcohol consumption and reproductive factors in a casecontrol study breast cancer in Moscow. International journal of cancer, 1991, 48:493-501.

20. De Stefani E et al. Dietary fiber and risk of breast cancer: a case-control study in Uruguay. Nutrition and cancer, 1997, 28:14-9.

21. Levi $F$ et al. Dietary factors and breast cancer risk in Vaud, Switzerland. Nutrition and cancer, 1993,19:327-35.

22. Boyd NF et al. Dietary fat and breast cancer risk revisited: a meta-analysis of the published literature. British journal of cancer, 2003, 89:1672-85. 